\title{
Propriedade intelectual de cultivares frutícolas e olerícolas no Brasil
}

\author{
Intellectual property of fruit and vegetable cultivars in Brazil \\ Propriedad intelectual de cultivares y hortalizas em Brasil
}

Recebido: 25/01/2022 | Revisado: 02/02/2022 | Aceito: 04/02/2022 | Publicado: 06/02/2022

\author{
Leila Moura Soares Nunes \\ ORCID: https://orcid.org/0000-0003-0217-6838 \\ Universidade Federal de Sergipe, Brasil \\ E-mail: leilamourasn@gmail.com \\ Ana Karla de Souza Abud \\ ORCID: https://orcid.org/0000-0001-6610-6084 \\ Universidade Federal de Sergipe, Brasil \\ E-mail: ana.abud@gmail.com
}

\begin{abstract}
Resumo
O estudo teve como objetivo fazer um amplo mapeamento das proteções de cultivares de frutíferas e olerícolas em vigor no Sistema Nacional de Proteção de Cultivares (SNPC), ligado ao Ministério da Agricultura, Pecuária e Abastecimento (MAPA), identificando a participação dos setores públicos e privados. A pesquisa, de caráter exploratório, foi realizada no portal CultivarWeb, sendo as proteções agrupadas de acordo com a natureza das instituições obtidas e separadas em tipo/espécie, setor e tipo de obtentor da cultivar. Foram encontrados 250 títulos de frutíferas, destacando-se as culturas da uva, maçã e morango, e 191 títulos de olerícolas, onde se sobressaíram a alface, o tomate e o melão. Observou-se um domínio do setor privado com 50,4\% das proteções para as cultivares frutíferas e 58,6\% para as olerícolas, seguido pelo setor público, com 36,0 e 30,4\%, respectivamente. A Embrapa foi a empresa que mais se destacou, com 18,6\% dos títulos de proteção destas culturas, mas um fator que chamou a atenção foi o domínio estrangeiro, com $14,1 \%$ dos registros, especialmente para as cultivares de frutas, onde $60,4 \%$ das proteções foram de não residentes. Os resultados indicam a necessidade de o Brasil, mesmo com ótimas condições climáticas e extensa territorialidade do país, investir mais em tecnologia para o desenvolvimento e conservação da cadeia frutífera e olerícola, oriunda, principalmente, da agricultura familiar, visando atender tanto a demanda interna quanto aumentar a participação no mercado externo.
\end{abstract}

Palavras-chave: Cultivar; Proteção; Alimento.

\begin{abstract}
The study aimed to carry out a broad mapping of the protections of fruit and vegetable cultivars operative in the National System for the Protection of Cultivars (SNPC), linked to the Ministry of Agriculture, Livestock and Supply (MAPA), identifying the participation of the public and private sectors. The research, exploratory, was carried out on the CultivarWeb portal, with the protections grouped according to the nature of the institutions obtained and separated into type/species, sector and type of breeder of the cultivar. 250 titles of fruit cultivars were found, highlighting the crops of grape, apple and strawberry, and 191 titles of vegetable cultivars, where lettuce, tomato and melon stood out. There was a dominance of the private sector with $50.4 \%$ of protections for fruit cultivars and $58.6 \%$ for vegetable crops, followed by the public sector, with 36.0 and $30.4 \%$, respectively. Embrapa was the company that stood out the most, with $18.6 \%$ of the protection titles for these crops, but a factor that drew attention was the foreign domain, with $14.1 \%$ of the registrations, especially for fruit cultivars, where $60.4 \%$ of protections were from non-residents. The results indicate the need for Brazil, even with excellent climatic conditions and extensive territoriality of the country, to invest more in technology for the development and conservation of the fruit and vegetable chain, originating mainly from family farming, in order to meet both domestic and domestic demand, and increase participation in the foreign market.
\end{abstract}

Keywords: Cultivar; Protection; Food.

\section{Resumen}

El estudio tuvo como objetivo realizar un mapeo amplio de las protecciones de cultivos frutícolas y olerícolas vigentes en el Sistema Nacional de Protección de Cultivares (SNPC), vinculado al Ministerio de Agricultura, Ganadería y Abastecimiento (MAPA), identificando la participación de lo publico y lo privado. La investigación, de carácter exploratorio, se realizó en el portal CultivarWeb, con las protecciones agrupadas según la naturaleza de las instituciones obtenidas y separadas por tipo/especie, sector y tipo de obtentor del cultivar. Se encontraron 250 títulos de frutales, destacándose los cultivos de uva, manzano y fresa, y 191 títulos de cultivos de hortalizas, donde destacaron lechuga, tomate y melón. Hubo un predominio del sector privado con 50,4\% de protecciones para cultivares de frutas y 58,6\% para cultivos de hortalizas, seguido por el sector público, con 36,0 y 30,4\%, respectivamente. Embrapa fue la empresa que más se destacó, con el 18,6\% de los títulos de protección para estos cultivos, pero un factor que llamó la atención fue el dominio extranjero, con el $14,1 \%$ de los registros, especialmente para los cultivares frutales, donde el 60,4\% de 
las protecciones fueron de non residentes. Los resultados indican la necesidad de que Brasil, aún con excelentes condiciones climáticas y amplia territorialidad del país, invierta más en tecnología para el desarrollo y conservación de la cadena hortofrutícola, proveniente principalmente de la agricultura familiar, con el fin de atender a los consumidores domésticos y demanda interna aumentar la participación en el mercado externo.

Palabras clave: Cultivar; Proteccion; Alimento.

\section{Introdução}

Com o desenvolvimento tecnológico, Cordeiro e Romeiro (2020) citam que a propriedade intelectual, inicialmente dividida entre direito autoral e propriedade industrial, necessitou de outras formas de proteção, como é o caso da categoria sui generis, onde se insere a proteção de cultivares.

Uma cultivar é, na definição de Wilkinson e Castelli (2000), a variedade de planta cultivada e utilizada na agricultura que, por força da seleção do homem, foi melhorada (modificada), tornando-se mais homogênea do que a variedade silvestre que lhe deu origem, podendo ser híbrida ou transgênica. Assim, a cultivar é um vegetal que não se desenvolve de modo natural, sendo obtida por meios biotecnológicos.

A propriedade intelectual sobre variedades vegetais foi introduzida definitivamente no mundo a partir da criação da União Internacional sobre Proteção de Variedades Vegetais (UPOV), em 1961, ao reconhecer a importância e a necessidade de se construir sistemas efetivos de proteção para novas variedades de plantas, obtidas por meio de melhoramento genético (Aviani; Machado, 2011).

No Brasil, as cultivares são protegidas meio da Lei no 9.456/1997 (Lei de Proteção de Cultivares - LPC), regulamentada pelo Decreto no 2.366, de 5 de novembro de 1997, do Ministério da Agricultura, Pecuária e Abastecimento (MAPA). Mesmo sendo signatário da Ata da UPOV de 1978 (Ferreira; Oliveira, 2012), o país estabelece um sistema próprio de proteção, o sistema sui generis, tendo em vista que, de antemão, a legislação brasileira não permite a patente de seres vivos (Brasil, 1997).

No conceito técnico, trazido pela norma, as características necessárias para que essa nova variedade de planta seja passível de proteção, envolvem: (1) ser uma variedade de qualquer gênero ou espécie vegetal superior; (2) ser distinguível de outras cultivares já existentes; (3) ter denominação própria; (4) ser homogênea; (5) permanecer estável nas características descritas ao longo de sucessivas gerações; e (6) ser passível de uso pelo complexo agroflorestal, ou pertencer a uma linhagem componente de híbridos (Brasil, 1997).

De acordo com Cordeiro e Romeiro (2020), a proteção garantida pela LPC se refere ao melhoramento genético vegetal tradicional, sem aplicação de modificações genéticas artificiais, visto que plantas transgênicas, ou seja, modificadas geneticamente, seguem a Lei n 9.279/1996 (Lei de Propriedade Industrial - LPI) e a Lei n 11.105/2005 (Lei de Biossegurança), com os pedidos de liberação para comercialização tramitados individualmente pela Comissão Técnica Nacional de Biossegurança (CNTBio).

A propriedade intelectual de cultivares é concedida, fiscalizada e coordenada no Brasil pelo Serviço Nacional de Proteção de Cultivares (SNPC), ligado ao Ministério da Agricultura, Pecuária e Abastecimento (MAPA). Este órgão tem como objetivo incentivar o desenvolvimento de cultivares superiores, garantindo proteção ao setor de melhoramento vegetal, com resultados imediatos nas instituições de pesquisas agropecuárias e no setor produtivo de sementes. Após análise e obedecidos os preceitos legais, é emitido o Certificado de Proteção pelo SNPC, considerado um bem móvel e a única forma de proteção das espécies superiores de plantas (MAPA, 2017).

O critério de novidade é atemporal e diz respeito ao tempo de comercialização ou não da cultivar e, não, no sentido de ser algo novo, como ocorre com as patentes (Santos et al., 2020). Assim, de acordo com a Lei nº 9.456/1997, art. $3^{\circ}$, V, a cultivar é considerada nova e, portanto, passível de proteção, quando não tenha sido oferecida à venda ou comercializada no Brasil há mais de doze meses em relação à data do pedido de proteção, além de não ter sido oferecida à venda em outros países, com o 
consentimento do obtentor, há mais de 6 anos para espécies de árvores e videiras e há mais de 4 anos para as demais espécies (Brasil, 1997).

Quanto à duração da proteção, a cultivar é protegida pelo prazo de 15 anos a partir do Certificado Provisório de Proteção, à exceção das videiras e árvores (frutíferas, florestais e ornamentais), inclusive, em cada caso, o seu porta-enxerto, para os quais a duração é de 18 anos (MAPA, 2017).

A comercialização da cultivar no Brasil é feita por meio do Registro Nacional de Cultivares (RNC), ligado ao Ministério da Agricultura, Pecuária e Abastecimento (MAPA) e regido pela Lei no 10.711/2003 (Lei de Sementes e Mudas), responsável por autorizar previamente a cultivar para a produção, beneficiamento e comercialização de sementes e mudas no País. Essa lei define comércio como o ato de anunciar, expor à venda, ofertar, vender, consignar, importar ou exportar sementes ou mudas. Isso faz com que o obtentor se atenha a determinadas ações promocionais ou de lançamento das cultivares para não colocar em risco a sua novidade (Aviani, 2011).

Diante das intensas mudanças climáticas, o grande desafio para o agronegócio é aumentar a produtividade para suprir a demanda por alimentos, preservando os recursos naturais e a biodiversidade (FAO, 2017).

Para se alcançar uma agricultura sustentável devem ser desenvolvidos mecanismos de manejo agrícola para reduzir ao máximo os danos ambientais, com emprego de tecnologias menos agressivas, otimização da produção, proteção, preservação e melhorados recursos naturais, ou seja, utilização de forma eficiente do solo, o que esbarra, muitas vezes, em interesses econômicos distintos (Assad; Almeida, 2004).

Neste contexto, o Brasil tem papel de destaque na produção de alimentos, pois ainda tem a possibilidade de aumento de terras para a agricultura, diferente de outros países que esgotaram suas terras agrícolas, como os EUA e China. A olericultura ocupa posição de destaque por ser responsável pelo maior número de espécies consumidas pela humanidade, englobando folhas, raízes, bulbos, tubérculos, frutos e diversas outras partes comestíveis de plantas.

Além de se destacar entre os maiores produtores e exportadores de grãos, frutas, fibras e proteínas (Bonissoni, 2021), Saath e Fachinello (2018) põem o Brasil no centro mundial para elevar a produção de alimentos e ser garantidor da segurança alimentar, tanto interna quanto a nível internacional. Todavia, alertam para o fato dos problemas advindos das mudanças climáticas, devendo-se pensar em uma agricultura que não avance nas florestas tropicais e não desmate.

As inovações tecnológicas nas cultivares, oriunda de produtores, agroindústrias, empresas e Instituições Científicas, Tecnológicas e de Inovação (ICTs), aliada a práticas sustentáveis, vieram, então, como resposta ao grande desafio no mundo em atender as necessidades da segurança alimentar, buscando mitigar ou mesmo evitar o esgotamento dos recursos naturais, que são finitos. Trouxeram como vantagens o aumento da capacidade produtiva e uma maior eficiência, aliadas às práticas adequadas de manejo do solo, reduzindo o uso de defensivos de pragas e doenças, melhorando a capacidade nutritiva e contribuindo para o desenvolvimento sustentável, garantindo a todos o acesso regular a alimentos, suficientes e de qualidade (Bruch; Dewes; Vieira, 2015).

Diante desse cenário o presente estudo tem como objetivo analisar a propriedade intelectual de cultivares de frutíferas e olerícolas no país. O estudo é importante em função do aumento da demanda desse tipo de alimento, evidenciando o quanto o setor é rentável e promissor, cumprindo uma função social importante ante a situação de desemprego que o país passa. Desta forma, investir em tecnologia de melhoramento de vegetais nessas classificações é fundamental para o crescimento econômico, tendo em vista que o país oferece as condições agrícolas, climáticas e ambientais adequadas, podendo explorar a grandeza de variedades vegetais que o Brasil tem e não se encontra em outros locais. 


\section{Metodologia}

A pesquisa é caracterizada como quali-quantitativa e exploratória. Exploratória, por não se ter informação sobre determinado tema e desejar conhecê-lo (Gil, 1999). Quali-quantitativa por interpretar as informações quantitativas por meio de números e os dados qualitativos mediante a observação, para melhor conhecer o fenômeno estudado (Knechtel, 2014).

Os dados para o estudo foram extraídos do banco de dados do Sistema Nacional de Proteção de Cultivares (SNPC), ligado ao Ministério da Agricultura, Pecuária e Abastecimento (MAPA, e disponível no portal CultivarWeb (https://sistemas.agricultura.gov.br/snpc/cultivarweb), considerando as proteções em vigor até a data de 31 de novembro de 2021.

As proteções foram agrupadas de acordo com a natureza das instituições obtidas e classificadas por: (1) tipo/espécie de cultivar; (2) setor detentor da proteção [instituição pública, instituição privada (inclui, também, pessoa física) e parcerias]; (3) perfil dos titulares (residentes e não residentes). As informações foram inseridas em tabelas do Excel® e os dados foram apresentados utilizando estatística descritiva.

O Quadro 1 mostra as espécies protegidas no Serviço Nacional de Proteção de Cultivares (SNPC) segundo os seus respectivos grupos de cultivo, utilizado na pesquisa no campo "nome comum da espécie".

Quadro 1. Grupos de cultivo registrados no SNPC.

\begin{tabular}{|c|c|}
\hline ESPÉCIE & GRUPO DE CULTIVO \\
\hline Frutífera & $\begin{array}{c}\text { goiaba, kiwi, abacaxi, laranja, tangerina, morango, maçã, manga, banana, oliveira (azeitona), maracujá, guaraná, } \\
\text { abacate, nectarina, pêssego, romã, pêra, feijoa (goiaba do mato), framboesa, ameixa-japonesa, amora-preta, } \\
\text { mirtilo, videira (uva), cereja }\end{array}$ \\
\hline Olerícola & $\begin{array}{c}\text { alface, tomate, melão, cebola, cenoura, feijão-vagem, pimenta/pimentão, rúcula, berinjela, ervilha, melancia, } \\
\text { quiabo, chicória, coentro }\end{array}$ \\
\hline
\end{tabular}

Fonte: Elaborado pelos autores com base nos dados extraídos do SNPC/MAPA.

\section{Resultados e Discussão}

Foram encontrados 250 títulos de proteção de cultivar de espécies frutíferas (Tabela 1) e 191 de olerícolas (Tabela 2).

As espécies frutíferas com maiores quantidades de proteção foram a uva (31,6\%), a maçã $(15,6 \%)$, o morango $(8,4 \%)$, o pêssego (7,6\%) e o maracujá (5,2\%), enquanto as espécies de cereja, abacate, ameixa-japonesa, amora-preta, romã e goiaba têm o menor número de títulos.

Em relação às olerícolas, também denominadas de hortaliças, as cultivares de maior proteção foram alface $(42,4 \%)$, tomate $(18,8 \%)$, melão (11,5\%), cebola e pimenta (6,3\& cada) e cenoura (3,7\%). As demais culturas (feijão-vagem, pimentão, rúcula, beringela, ervilha, melancia, coentro, quiabo e chicória), juntas, somam apenas $11 \%$ dos cultivares protegidos, percentual menor do que o do melão. A alface, o tomate, o melão e a cebola, além de se destacarem como importantes cultivares olerícolas, também se configuram entre as hortaliças mais produzidas e consumidas no país. 
Tabela 1. Cultivares de frutíferas registradas no SNPC.

\begin{tabular}{|c|c|c|}
\hline Nome científico & Nome comum & Quantidade de títulos \\
\hline Vitis L. & uva/videira & 79 \\
\hline Malus domestica Borkh. & maçã & 34 \\
\hline Fragaria $\mathrm{L}$. & morango & 21 \\
\hline Prunus persica (L.) Batsch (Pêssego) & pêssego & 19 \\
\hline Passiflora edulis Sims & maracujá & 9 \\
\hline Olea europaea L. & oliveira/azeitona & 9 \\
\hline Rubus idaeus L. & framboesa & 8 \\
\hline Paullinia cupana Kunth var. sorbilis & guaraná & 8 \\
\hline Mangifera indica $\mathrm{L}$. & manga & 7 \\
\hline Citrus L. (Tangerinas) & tangerina & 7 \\
\hline Vaccinium $\mathrm{L}$. & mirtilo & 6 \\
\hline Malus Mill. (porta-enxerto) & maçã & 5 \\
\hline Acca sellowiana (Berg) Burret & feijoa & 4 \\
\hline Prunus persica (L.) Batsch (Nectarina) & nectarina & 4 \\
\hline Passiflora $\mathrm{L}$ & maracujá & 4 \\
\hline Musa L. & banana & 3 \\
\hline Citrus L. (Laranjas) & laranja & 3 \\
\hline Ananas comosus (L.) Merr. & abacaxi & 3 \\
\hline Actinidia Lindl. & kiwi & 3 \\
\hline Persea americana Mill. & abacate & 2 \\
\hline Prunus salicina Lindl. & ameixa-japonesa & 2 \\
\hline Rubus subg. Eubatus sect. Moriferi et Ursini & amora-preta & 2 \\
\hline Punica granatum L. & romã & 2 \\
\hline Pyrus communis L. (frutíferas) & pêra & 2 \\
\hline Psidium $\mathrm{L}$. & goiaba & 1 \\
\hline Prunus L. & cereja & 1 \\
\hline Psidium guajava $\mathrm{L}$. & goiaba & 1 \\
\hline Pyrus communis L. (porta-enxertos) & pêra & 1 \\
\hline
\end{tabular}

Fonte: Elaborado pelos autores com base nos dados extraídos do SNPC/MAPA.

Tabela 2. Cultivares de olerícolas registradas no SNPC.

\begin{tabular}{|c|c|c|}
\hline Nome científico & Nome comum & Quantidade de títulos \\
\hline Lactuca sativa $\mathrm{L}$ & alface & 81 \\
\hline Solanum lycopersicum L. & tomate & 36 \\
\hline Cucumis melo L. & melão & 22 \\
\hline Allium cepa $\mathrm{L}$. & cebola & 12 \\
\hline Daucus carota L. & cenoura & 7 \\
\hline Phaseolus vulgaris L. & feijão-vagem & 5 \\
\hline Capsicum annuum L. var. annuum (Pimenta) & pimenta & 4 \\
\hline Capsicum L. (Pimenta) & pimenta & 4 \\
\hline Capsicum chinense Jacq. & pimenta & 4 \\
\hline Capsicum L. (Pimentão) & pimentão & 3 \\
\hline Eruca sativa Mill. & rucula & 3 \\
\hline Solanum melongena $\mathrm{L}$. & beringela & 2 \\
\hline Pisum sativum $\mathrm{L}$. & ervilha & 2 \\
\hline Citrullus lanatus (Thunb.) Matsum. \& Nakai & melancia & 2 \\
\hline Coriandrum sativum $\mathrm{L}$. & coentro & 1 \\
\hline Abelmoschus esculentus (L.) Moench & quiabo & 1 \\
\hline Capsicum annuum L. var. annuum (Pimentão) & pimentão & 1 \\
\hline Cichorium endivia $\mathrm{L}$. & chicória & 1 \\
\hline
\end{tabular}

Fonte: Elaborado pelos autores com base nos dados extraídos do SNPC/MAPA.

Quanto ao tipo de setor que mais participa do processo de proteção dos cultivares de frutíferas e olerícolas (Figura 1), verifica-se um domínio acentuado do setor privado tanto para as frutíferas (50,4\%) quanto para as olerícolas (58,6\%). Na segunda posição vem o setor público, onde em frutíferas as instituições ficam com 36,0\% do total, cerca de 13,5\% menos do que o setor 
privado, indicando que o setor público é, também, um grande desenvolvedor desse tipo de tecnologia. A mesma situação não se observa nas olerícolas, pois as instituições públicas totalizam 30,4\% das obtenções, quase a metade da proteção obtida das instituições privadas, pondo-as com predomínio nessa classificação.

As parcerias são as que tem os menores valores de obtenções e isso se deve, provavelmente, aos poucos investimentos, não se tornando uma ação economicamente vantajosa. As parcerias privadas são inexistentes nas olerícolas e ínfimas nas frutícolas $(0,4 \%)$. As parcerias públicas têm $6,4 \%$ para frutíferas e apenas 2,6\% para olerícolas, uma baixa expressividade. A parceria público-privada, com a Lei nº 13.243/2016, também conhecida como Marco Legal de Ciência, Tecnologia e Inovação, passou a ter um ambiente mais propício de incentivo à inovação, avivando parcerias entre instituições públicas e privadas. Como reflexo, as obtenções de registros em frutíferas por esse tipo de parceria foi de 6,8\%, enquanto nas olerícolas resultaram em $8,4 \%$ do total das obtenções.

Figura 1. Participação dos setores na obtenção de cultivares no SNPC. (a) Frutíferas; (b) Olerícolas.

\section{(a) Frutíferas}

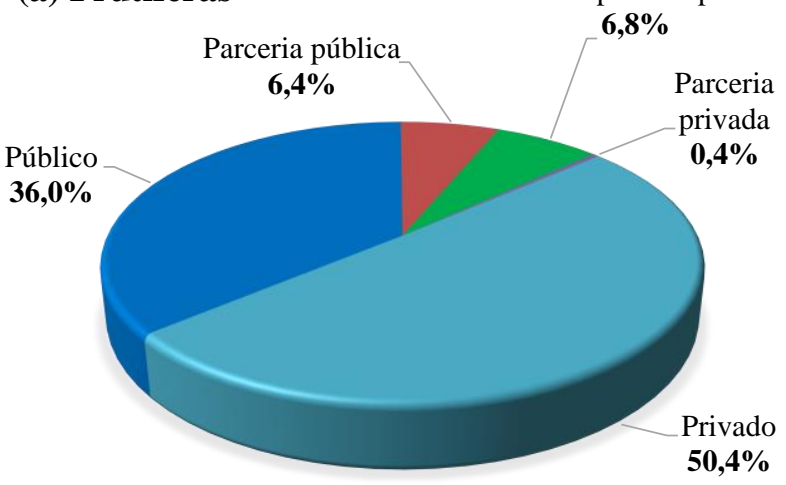

(b) Olerícolas

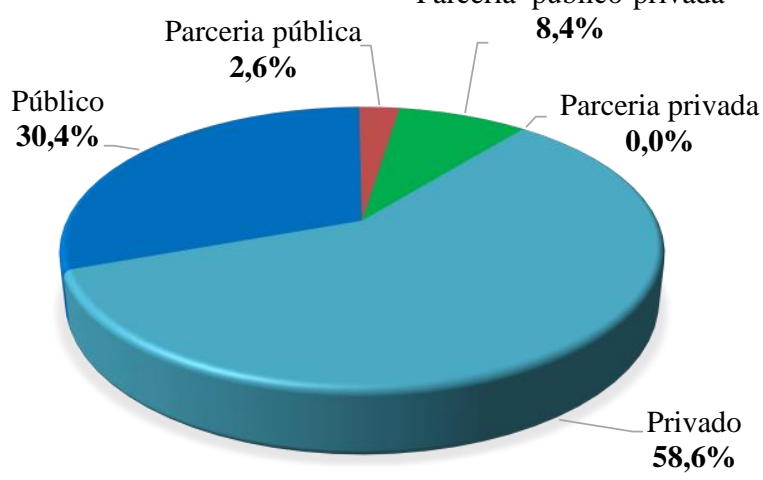

Fonte: Elaborado pelos autores com base nos dados extraídos do SNPC/MAPA.

Segundo Eusébio et al. (2016), nas parcerias público-privadas, às vezes, o parceiro privado entra com o aporte financeiro e o público com a pesquisa e o desenvolvimento da nova cultivar, podendo, então, considerar que o parceiro privado pode ter o direito exclusivo para registro de comercialização. Os autores ainda explicam que a baixa presença das instituições públicas é, justamente, devido à falta de incentivo das instituições de fomento (federais e estaduais) para o desenvolvimento de novas tecnologias. Isto explica, também, a presença tão ínfima da parceria pública nas olerícolas e maioria das parcerias sendo públicoprivadas.

O investimento no desenvolvimento de novas cultivares é uma situação que precisa ser revista pelos governos, tanto no âmbito federal quanto estadual e municipal, uma vez que as culturas agrícolas são bastante rentáveis e, também, exercem um papel de destaque nas questões sociais, econômicas, industriais e alimentar. O Brasil produziu 59 milhões de toneladas de frutas (FAOSTAT, 2021), deixando o país em terceiro lugar na produção mundial, ficando atrás da China e Índia, gerando, diretamente, 6 milhões de empregos, ou seja, 27\% dos empregos criados pela produção agrícola nacional, que ocupa uma área de 2,4 milhões hectares. Igualmente, as olerícolas foram responsáveis por gerar $\mathrm{R} \$ 25$ bilhões e 7 milhões de empregos direta e indiretamente. Estas cultivares geram alimentos que estão na mesa do consumidor e a tendência por questões de saudabilidade e bem-estar indicam a necessidade de uma maior produção (Hortifruti, 2018).

As instituições públicas obtiveram 90 títulos de frutíferas e 58 de olerícolas, ao passo que as instituições privadas lideram em termos de quantidade, com 126 títulos de frutíferas e 112 de olerícolas. Isto ocorre porque o setor observa um aumento da rentabilidade e crescimento no consumo, levando o brasileiro, em 2019, a ter um gasto médio de $16 \%$ a mais se comparado aos dados de 2018 (Hortifruti Brasil, 2022). 
Analisando a participação das principais cultivares frutíferas por setor (Figura 2), verifica-se que o setor público é obtentor de todos os títulos de maracujá, seja uma única instituição ou por parceria pública. O pêssego também tem uma importante participação do setor público, detendo 17 das 19 proteções.

Figura 2. Histograma de proteção dos cultivares das principais espécies de frutas por setor de obtenção.

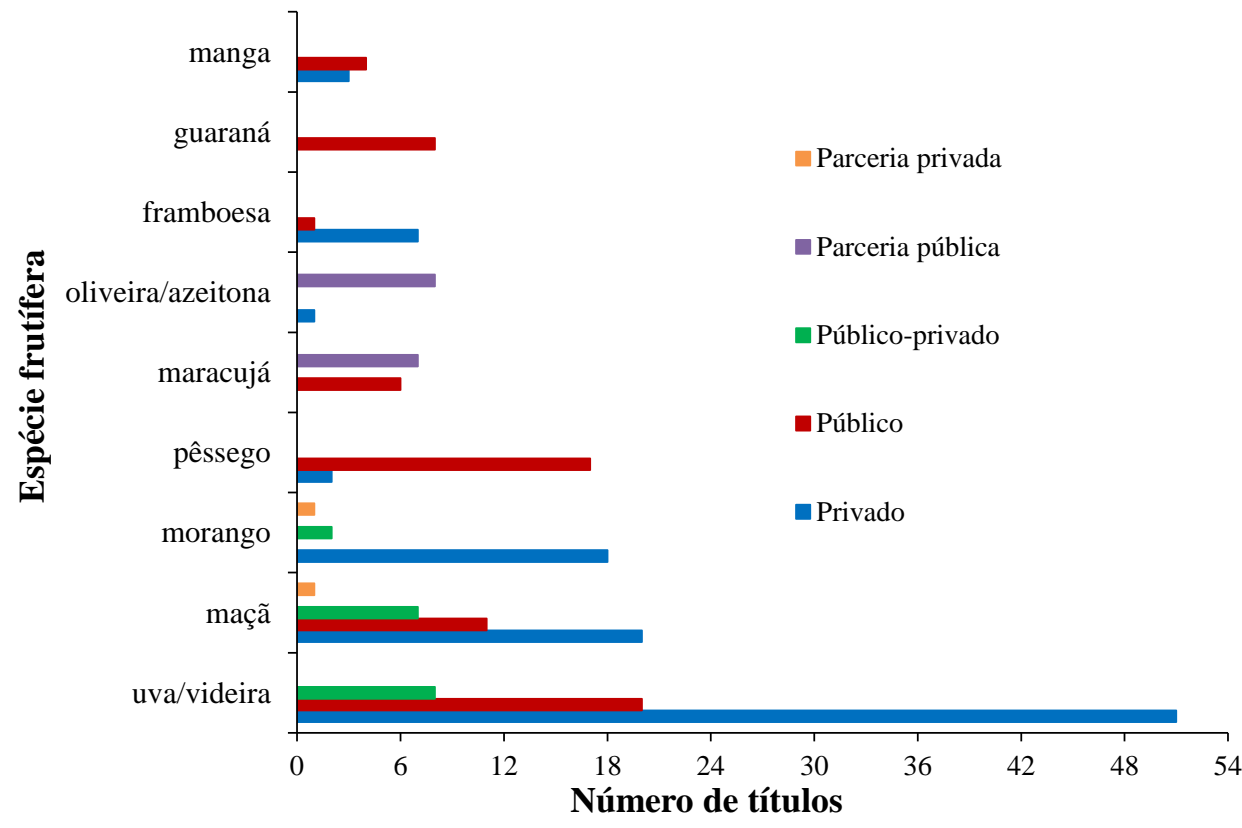

Fonte: Elaborado pela autora com base nos dados extraídos do SNPC/MAPA.

Além do maracujá, as parcerias públicas também se destacam para as cultivares de azeitona, com cerca de $90 \%$ das proteções oriundas da parceria da Fundação de Amparo à Pesquisa do Estado de Minas Gerais (FAPEMIG) com a Empresa de Pesquisa Agropecuária de Minas Gerais (EPAMIG). A proteção de cultivares no setor privado se sobressai para as culturas de uva, com 51 dos 79 títulos (64,6\%), maçã (51,3\%), morango (857\%) e framboesa (87,5\%). Para a cultivar da espécie de framboesa, a única parceria pública é de uma instituição estrangeira, a The New Zeland Institute for Plant and Food Research. As proteções do setor privado desta espécie são, também, de não residentes.

O guaranazeiro (Paullinia cupana var. sorbilis (Mart.) Ducke) é uma espécie nativa da Amazônia, de considerável valor econômico e social. Seu cultivo ocorre, principalmente, nos estados do Amazonas, Bahia e Mato Grosso, em decorrência, da demanda das sementes do guaraná pelas indústrias de bebidas, farmacêuticas e cosméticas, nacionais e internacionais. Dados da produção agrícola divulgados pelo Instituto Brasileiro de Geografia e Estatística (IBGE), em 2020, indicam a produção de 2.704 toneladas de guaraná, em uma área de 10.416 hectares, com valor total da produção um pouco maior que $\mathrm{R} \$ 37$ milhões (IBGE, 2022). Todas as cultivares protegidas de guaraná têm como detentor a Empresa Brasileira de Pesquisa Agropecuária (Embrapa).

Outra espécie com domínio de proteção predominantemente estrangeiro é a manga, que detém 3 proteções no setor privado ( 2 da Austrália e 1 da África do Sul) e 4 no setor público, todas de Israel.

Para a uva, a principal empresa detentora de proteção de cultivares é a Embrapa (16). Para a maçã, a Empresa de Pesquisa Agropecuária e Extensão Rural de Santa Catarina (EPAGRI), com 6 proteções. Para o morango, a The Regents of the University of California (8). Para o pêssego, 9 cultivares foram depositados pela Embrapa, enquanto 7 cultivares de maracujá têm como depositantes a parceria entre a Embrapa e a Fundação da Universidade de Brasília (FUB). A parceria entre a EPAMIG e a FEPAMIG permitiu a proteção de 8 cultivares de azeitona e a manga tem como principal depositante o Ministério da Agricultura de Israel, com 4 obtenções. 
Todavia, as cultivares de maior volume de produção e venda no país são pertencentes à laranja ( 1 título pertence a uma empresa da Austrália, 1 a uma empresa da África do Sul e 1 da Embrapa), ao abacaxi (1 cultivar dos Estados Unidos, 1 de Mônaco e 1 da Embrapa) e à banana, onde a Embrapa possui 3 cultivares protegidos atualmente.

As instituições públicas são as mais envolvidas, com maior participação da Embrapa. Entretanto, o que chama a atenção é o caso da manga, uma fruta tropical inserida entre as mais produzidas e consumidas no país e, também, exportada, tendo como maior obtentor dos cultivares Israel.

Quanto à participação das olerícolas por setor (Figura 3), as instituições públicas se destacam na proteção de cultivares de pimenta com 11 dos 12 títulos (91,7\%), de cenoura (85,7\%) e de cebola (75\%). Para o setor privado, a alface, maior detentora de cultivares protegidos, possui 70,4\% de participação, enquanto o tomate tem $75 \%$ e o melão, $81,8 \%$. A parceria público-privada tem destaque em obtenções de alface, com 18,8\% das proteções relativas a esta espécie.

Figura 3. Histograma de proteção dos cultivares das principais espécies de hortaliças por setor de obtenção.

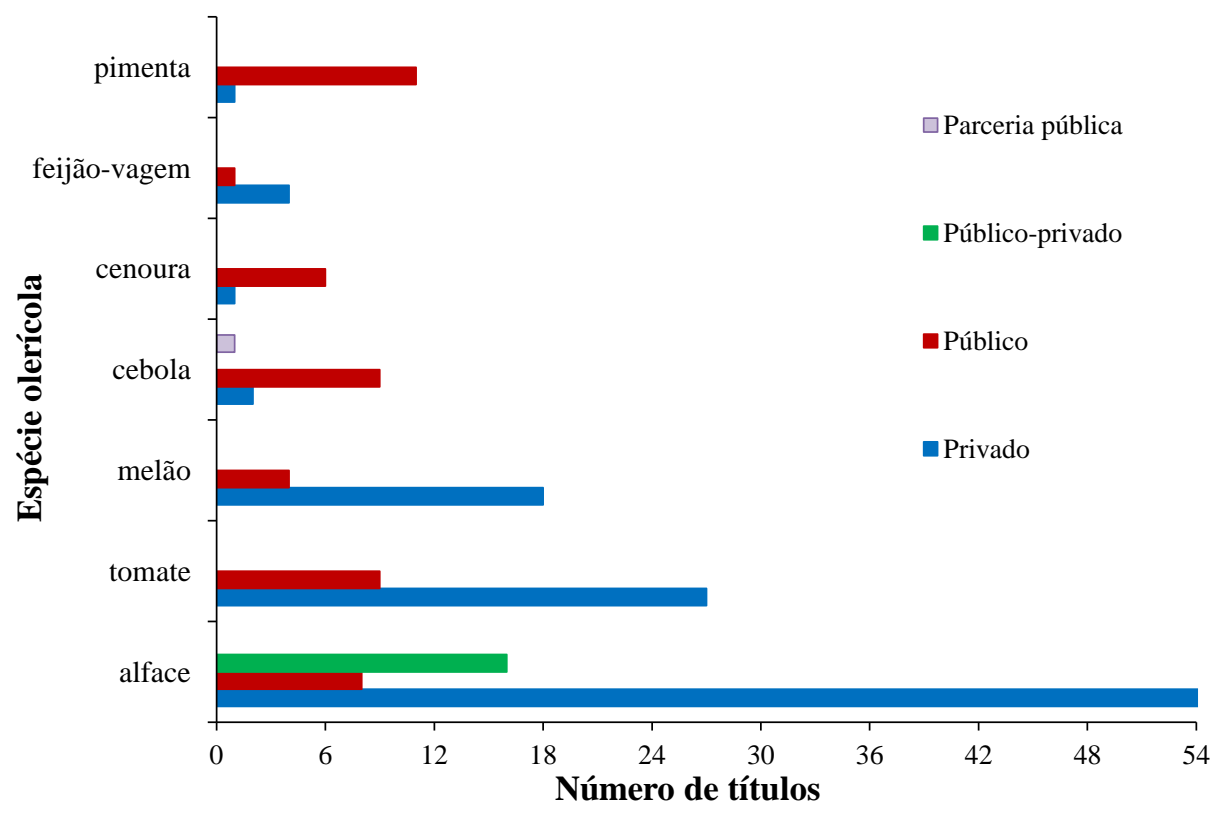

Fonte: Elaborado pela autora com os dados extraídos do SNPC/MAPA.

Entre as principais empresas detentoras de cultivares olerícolas, destacam-se a Sakata Seed Sudamerica, com 29 cultivares de alface e 3 de feijão-vagem, a Embrapa e a Syngenta, com 8 proteções cada para o tomate e a holandesa Rijk Zwaan Zaadteelt en Zaadhandel B.V. com 6 cultivares de melão. A cebola possui como principais detentores de seus cultivares a Embrapa e a EPAGRI, com 4 proteções cada. A Embrapa também é a maior detentora de proteções da pimenta ( 8 títulos) e da cenoura (6 títulos). A alface foi o único cultivar que apresentou proteções advindas de parceria público-privada, com todos os seus 16 títulos pertencentes à parceria entre a Universidade Federal de São Carlos (UFSCAR) e a empresa Feltrin Sementes.

Folhosa mais consumida no país, a alface tem uma produção estimada em 1,5 milhões de toneladas anuais, movimentando cerca de $\mathrm{R} \$ 8$ bilhões. Porém, em termos mundiais, a produção do Brasil é considerada inexpressiva e com os baixos investimentos, sendo os dados de produção excelentes apenas para o mercado interno. A China é a maior produtor mundial da folha, com uma produção 23,6 milhões de toneladas, o que equivale a 52\% da produção mundial (Pessoa; Machado Junior, 2021).

O tomate, bastante apreciado no país, produziu em 2019, segundo o IBGE, cerca de 4 milhões de toneladas em uma área de 54,5 mil hectares, com um rendimento médio de 71,8 toneladas por hectare, o que rendeu R\$ 1 bilhão de produção. 
Dados da Organização das Nações Unidas para a Alimentação e a Agricultura (FAO) apontam o Brasil na $9^{a}$ posição de produtores da hortaliça, mas sua contribuição com o mercado externo é de somente $0,1 \%$ de tomates frescos (FAOSTAT, 2021). A Argentina foi o país para onde mais se exportou tal produto, seguido por Paraguai e Uruguai (CONAB, 2016).

De acordo com Gomes (2016), o melão é, atualmente, o principal responsável pela exportação de hortaliças do país, em uma área plantada de cerca de 25 mil hectares, dos quais 22 mil ficam na região Nordeste, nos Estados do Rio Grande do Norte, Ceará e Pernambuco. Caracterizada por sua qualidade e durabilidade, $80 \%$ da produção da fruta produzida nos Estados do Rio Grande do Norte e Ceará são destinados quase que exclusivamente à exportação, onde a Europa é o principal consumidor, destacando-se a Espanha, os Países Baixos e o Reino Unido (Travaglini; Marchesi; Barbieri, 2021). A China abriu o mercado para a produção da fruta, o que tende a crescer a sua produção e exportação.

Apesar de as produções terem se mostrado expressivas, é necessário um maior aporte de investimentos ante a importância não só econômica, mas, principalmente, social das duas classificações abordadas neste estudo, uma vez que são características de pequenos produtores e/ou agricultura familiar.

Dentro deste contexto, torna-se fundamental analisar o perfil dos obtentores de cultivares de frutíferas e olerícolas no Brasil cadastrados no SNPC (Figura 4).

Figura 4. Perfil dos obtentores de PI de cultivares no SNPC/Brasil.(a) Frutíferas; (b) Olerícolas.

(a) Frutíferas

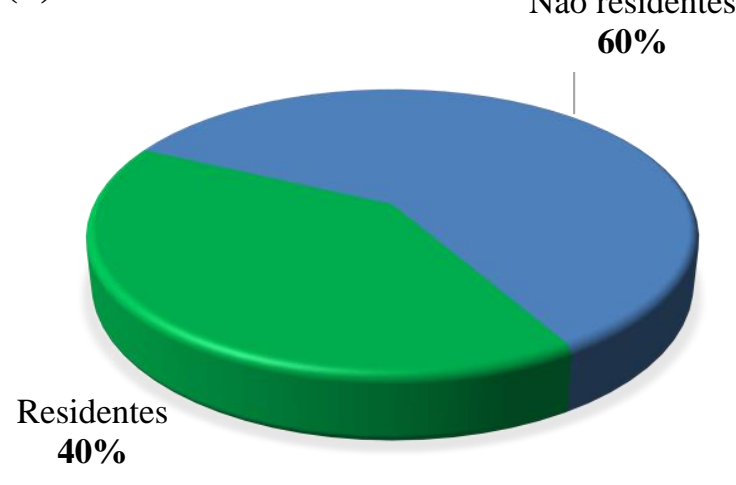

(b) Olerícolas

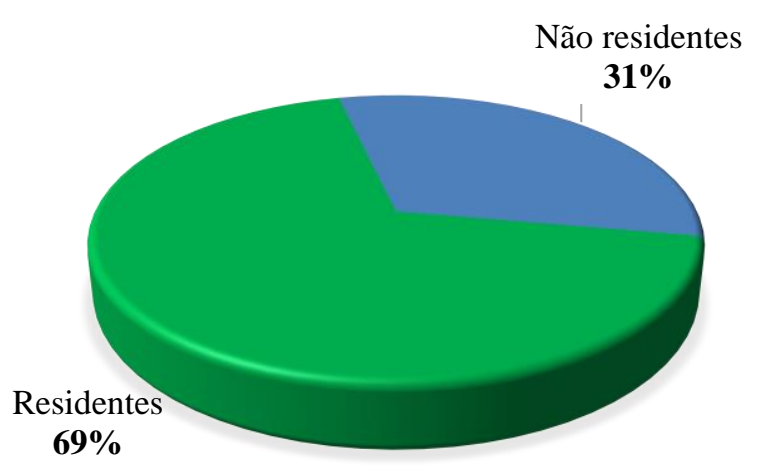

Fonte: Elaborado pelos autores a partir de dados extraídos da base do SNPC/MAPA.

Os obtentores não residentes de frutíferas (Figura 4a) têm a maioria dos títulos, ou seja, 149 dos 250 títulos em vigor, representando 59,6\% do total de obtenções, uma quantidade significativa ainda que o Brasil seja considerado o terceiro maior produtor de frutas do mundo. Com um mercado interno rentável e com as condições climáticas favoráveis para esse tipo de cultura, a proteção de cultivares por instituições estrangeiras se torna atraente. Instituições dos Estados Unidos estão entre os maiores obtentores estrangeiros, ficando com 65 títulos (43,6\%). Em seguida vem Espanha, com 15 títulos (10,1\%), e a Nova Zelândia, com 12 títulos (8,1\%), todos de uma instituição pública. No ranking das empresas estadunidenses, a International Fruit Genetics, LLC e a Sheehan Genetics LLC possuem 14 títulos cada, sendo seguida pela The Regents of the University of California, com 9 títulos.

Os residentes têm 101 títulos de cultivares de frutíferas (40,4\%). Esta menor proporção em relação aos não residentes pode ser explicada pelo baixo investimento no setor, mesmo sendo o país um produtor mundial importante e com todas as possibilidades de elevar sua produção por ser um dos poucos países do mundo com terra e clima favoráveis para produzir o ano todo e em todas as regiões.

A região Nordeste se mostrou a maior produtora de frutas do país, principalmente os estados da Bahia, Rio Grande do Norte, Ceará e Pernambuco que, com investimentos em tecnologias modernas, foram responsáveis por $70 \%$ de toda a fruta 
exportada do Brasil em 2019 (ABRAFRUTAS, 2022). Em participação de instituições, a EMBRAPA, com 47 títulos, é a maior obtentora de registros de cultivares de frutas do país, ficando em primeiro lugar no ranking.

O cenário muda quando são analisados os dados das olerícolas (Figura 4b), onde os não residentes têm 60 títulos (31,41\% do total), ficando abaixo da metade dos residentes, que têm 131 títulos (68,58\%). Esta situação pode ser compreendida e relacionada à produção e rentabilidade do setor, atraindo a presença das empresas para esse tipo de comércio, quase que totalmente usada para abastecer o mercado interno, à exceção do melão, onde mais da metade é exportado. Nessa área, só as parcerias públicas têm participação ínfima, por conta da falta de incentivos nas instituições de fomento.

A Figura 5 apresenta as principais empresas/instituições com proteções de cultivares frutíferas e olerícolas no SNPC.

Figura 5. Principais empresas e instituições obtentoras de PI de cultivares frutíferas e olerícolas.

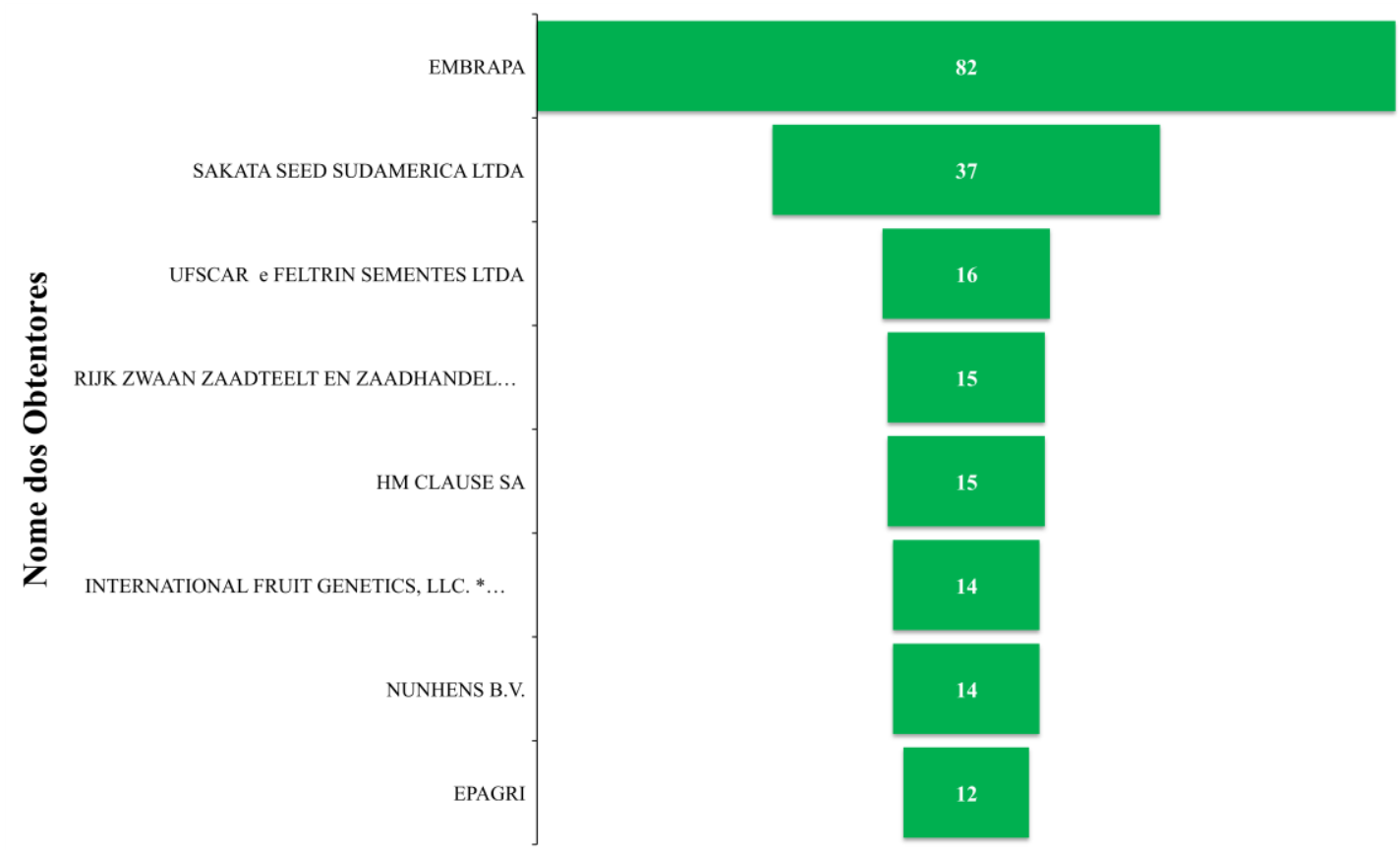

Fonte: Elaborado pela autora com base nos dados extraídos do SNPC/MAPA.

Nota-se um maior destaque para a Embrapa, com 82 títulos, respondendo a 18,6\% dos pedidos de proteção. Em segundo lugar, com 37 títulos (8,4\%), a empresa brasileira Sakata (www.sakata.com.br), que em 1994 adquiriu a empresa Agroflora, fundada em 1968, e é voltada à criação de variedades de hortaliças e flores que contribuem para o bem-estar das pessoas. Em terceiro, uma parceria público-privada entre a Universidade Federal de São Carlos (UFSCAR) e a empresa brasileira Feltrin Sementes (www.sementesfeltrin.com.br), com 16 títulos (3,6\%).

Entretanto, um fator que se destaca é o domínio estrangeiro, aparecendo em 5 posições com empresas privadas, sendo 3 dos Estados Unidos (Sheehan Genetics LLC, International Fruit Genetics LLC e The Regents of the University of California), uma da França (HM Clause AS) e uma dos Países Baixos (Rijk Zwaan Zaadteelt en Zaadhandel B.V.). Juntas, somam 14,1\% dos pedidos de proteção.

É nítido o sucesso da Embrapa nos dois tipos de culturas no país e seu sucesso se dá por ter desenvolvido cultivares e sementes muito bem adaptadas às condições de clima de cada região, repassando materiais genéticos mais produtivos e saudáveis. As novas variedades obtidas e mais adaptadas às condições edafoclimáticas do país foram responsáveis por manter o Brasil como um dos maiores produtores de alimentos do mundo (Embrapa, 2018). 
Contudo, diante da grandeza de variedades de frutas e hortaliças que o país tem, ao confrontar com a quantidade de cultivares, é nítido que não se investe o suficiente no setor, não se explora toda a grandeza de variedades e nem a capacidade produtiva do país, mesmo tendo elevado potencial de mercado.

Por isso o Brasil atrai tanto empresas estrangeiras, que veem o potencial do país com um grande produtor de alimentos, reunindo condições climáticas, ambientais e territoriais favoráveis para a expansão da produção em níveis globais. Estas condições, com o adequado investimento, poderiam tornar o país em líder mundial na produção de alimentos, desde que observadas as práticas ambientais e os compromissos com o clima e na redução do desmatamento florestal.

Essa perspectiva sobre o país também se alinha ao prognóstico da FAO sobre uma maior busca por alimentos naturais e mais saudáveis. A estimativa de atender a demanda por alimentos deve aumentar em mais de $70 \%$ até 2050 , quando a população mundial deverá alcançar os quase 10 bilhões de habitantes (FAO, 2015).

O Brasil, diferente das grandes nações produtoras de alimentos no mundo, é considerado o único país que ainda pode aumentar sua capacidade de produção alimentar, com o uso um pouco maior de terras agricultáveis, situação que China e Estados Unidos, por exemplo, não possuem (Saath \& Fachinello, 2018).

Todo este cenário mostra que o Brasil tem potencial e ferramentas necessárias para se tornar o maior produtor de alimentos do mundo, ante sua biodiversidade e seu potencial hídrico, mas é necessário investir em mais tecnologia e inovação no setor, para se produzir mais sem degradar. Isto pode ser possível com uma simples substituição de cultura, pequenos ajustes de produtividade, principalmente com o desenvolvimento de cultivares mais resistentes e seguras, e/ou realocações produtivas para atender essa demanda trazida pela FAO (Saath \& Fachinello, 2018).

Ante as situações geográficas e climáticas desfavoráveis, é primordial o fomento em investimentos para as instituições públicas, pois são elas as maiores fornecedoras de serviço intelectual e de pesquisa no país. Oferecem, ainda infraestrutura como laboratórios, casa de vegetação, campos experimentais e um amplo reservatório de genes nos seus bancos de germoplasma, conseguido através de anos de pesquisa, fomentando as parcerias público-privadas (Euzébio et al., 2016).

\section{Considerações Finais}

O mapeamento encontrou 250 títulos de frutíferas, destacando-se as culturas da uva, maçã e morango, e 191 títulos de olerícolas, onde se sobressaíram as cultivares de alface, tomate e melão. Os resultados indicaram um domínio do setor privado com 50,4\% das proteções para as frutíferas e 58,6\% para as olerícolas, seguido pelo setor público, com 36,0 e 30,4\%, respectivamente.

O Brasil é considerado um grande produtor de frutas e hortaliças, com mercado bastante rentável e um futuro promissor com grandes perspectivas de aumento na demanda. O país conta, também, com condições ambientais e climáticas que oferecem a oportunidade de aumentar a capacidade produtiva, tanto para atender o mercado interno quanto aumentar a participação no mercado externo.

Todavia, apesar da grandeza de variedades vegetais encontrada, o setor agrícola ainda carece de investimentos em tecnologia, desenvolvendo novas variedades de plantas melhoradas, principalmente para o mercado externo, principalmente para as frutíferas, onde mais de $60 \%$ das cultivares protegidas são oriundas de não residentes.

A falta de fomento ficou ainda mais nítida nas instituições públicas, com participação ínfima ante o setor privado, com a presença marcante de estrangeiros, grandes produtores de frutas, como os Estados Unidos e os Países Baixos. A exceção no setor público brasileiro no que tange a quantidade de títulos e investimentos em pesquisa nas áreas das frutíferas e olerícolas é a Embrapa, detendo 18,6\% das obtenções de cultivares no país.

Sugere-se, para trabalhos futuros, um levantamento de políticas públicas e de investimentos direcionados a este setor nos últimos anos, de forma a atrair a atenção e estimular o processo de inovação. 


\section{Agradecimentos}

O presente trabalho foi realizado com apoio da Coordenação de Aperfeiçoamento de Pessoal de Nível Superior - Brasil (CAPES) - Código de Financiamento 001.

\section{Referências}

ABRAFRUTAS - Associação dos Produtores e Exportadores de Frutas e Derivados (2022). Dados estatísticos. https://abrafrutas.org/dados-estatisticos/

Antunes, S., Almeida, R. P., Araújo, T. L. R., Follmann, D. N. \& Picon, L. C. (2014). Aspectos legais da lei de cultivares no Brasil. Revista Enciclopédia Biosfera, 10(18), 4024-4037.

Assad, M. L. L. \& Almeida, J. (2004). Agricultura e sustentabilidade: contextos, desafios e cenários. Revista Ciência \& Ambiente, $29,5-30$.

Aviani, D. M. \& Machado, R. Z. (2011). União Internacional para Proteção das Obtenções Vegetais (UPOV). https://www.gov.br/agricultura/ptbr/assuntos/insumos-agropecuarios/insumos-agricolas/protecao-de-cultivar/informacoes-publicacoes/livro-protecao-de-cultivares.pdf

Aviani, D. M. (2011) Requisitos para Proteção. https://www.gov.br/agricultura/pt-br/assuntos/insumos-agropecuarios/insumos-agricolas/protecao-decultivar/informacoes-publicacoes/livro-protecao-de-cultivares.pdf

Bonissoni, K. (2019). Melão brasileiro se destaca no mercado internacional. https://revistacultivar.com.br/noticias/melao-brasileiro-se-destaca-no-mercadointernacional

Brasil (1997). Lei de Proteção de Cultivares. http://www.planalto.gov.br/ccivil_03/leis/19456.htm

Bruch, K. L., Dewes, H. \& Vieira, A. C. P. (2015). Proteção de cultivares e patentes de invenção: uma coexistência possível. PIDCC, 9(4), 67-93.

Carvalho, A. V., Santos, L. C. X., Oliveira, M. C. G., Pereira, W. E. L., Ghesti, G. F. \& Melo, L. R. (2020). Transferência de cultivares no contexto nacional. https://www.atenaeditora.com.br/post-ebook/3190\#4a

CONAB - Companhia Nacional de Abastecimento (2016). Tomate: Análise dos indicadores da produção e comercialização no mercado mundial, brasileiro e catarinense. Compêndio de estudos, v. 21, 2016.

Cordeiro, F. L. \& Romeiro, L. A. S. (2020). O uso próprio de sementes salvas e suas relações com o direito de propriedade intelectual dos obtentores vegetais brasileiros. Cadernos de Prospecção, 13(4), 957-973.

Embrapa (2018). Visão 2030: o futuro da agricultura brasileira. https://www.embrapa.br/documents/10180/9543845/Vis\%C3\%A3o+2030++o+futuro+da+agricultura+brasileira/2a9a0f27-0ead-991 ${ }^{\mathrm{a}}$-8cbf-af8e89d62829.

Euzébio, M. P., Gomes, G., Gonçalves, L. S. A., Sekyia, A., Robaina, P. R. \& Marinho, C. D. (2016). Registro e proteção de olerícolas no Brasil, período de 1998 a 2014. Revista Horticultura Brasileira, 34, 19-26.

FAO (2009). How to feed the world in 2050. https://www.fao.org/fileadmin/templates/wsfs/docs/expert_paper/How_to_Feed_the_World_in_2050.pdf

FAO (2017). The future of food and agriculture: Trends and challenges. https://www.fao.org/3/i6583e/i6583e.pdf

FAOSTAT (2021). Production indices. https://www.fao.org/faostat/en/\#data/QI

Ferreira, N. B. V. \& Oliveira, P. S. (2012). Propriedade intelectual e melhoramento vegetal: uma análise da lei de cultivares. Âmbito Jurídico, 2 , 2-12.

Gil, A. C. (1999). Métodos e técnicas de pesquisa social. Atlas.

Gomes, J. L. (2016). Área técnica: olericultura. http://www.emater.tche.br/site/area-tecnica/sistema-de-producao-vegetal/olericultura.php\#.YdzY1vnMLrd

Hortifruti (2018). Relatório Cenário Hortifruti Brasil 2018 mostra que geração de empregos é destaque. https://saberhortifruti.com.br/cenario-hortifruti-brasil2018/

Hortifruti Brasil (2022). Anuário 2021-2022. https://www.hfbrasil.org.br/br/revista/acessar/completo/anuario-hf-brasil-retrospectiva-2021-perspectiva2022.aspx

IBGE - Instituto Brasileiro de Geografia e Estatística (2022). Produção Agropecuária. https://www.ibge.gov.br/explica/produção-agropecuaria/

Knechtel, M. R. (2014). Metodologia da pesquisa em educação: uma abordagem teórico-prática. Intersaberes.

MAPA - Ministério da Agricultura, Pecuária e Abastecimento (2017). Registro Nacional de Cultivares - RNC. https://www.gov.br/agricultura/pt-br/guia-deservicos/registro-nacional-de-cultivares-rnc

Pessoa, H. P. \& Machado Junior, R. (2021). Folhosas: em destaque no cenário nacional. Revista Campos e Negócios. https://revistacampoenegocios.com.br/folhosas-em-destaque-no-cenario-nacional/

Saath, K. C. O. \& Fachinello, A. L. (2018). Crescimento da demanda mundial de alimentos e restrições do fator terra no Brasil. Revista de Economia e Sociologia Rural, 56(2), 195-212. 
Research, Society and Development, v. 11, n. 2, e59011226162, 2022

(CC BY 4.0) | ISSN 2525-3409 | DOI: http://dx.doi.org/10.33448/rsd-v11i2.26162

Santos, L. C. X., Giordano, M. C, Pereira, W. E. L, Ghesti, G. F. \& Melo, L. R. (2020). Principais aspectos da proteção das cultivares no contesto nacional e internacional. https://sistema.atenaeditora.com.br/index.php/admin/api/artigoPDF/35320

SEAB - Secretaria de Estado da Agricultura e do Abastecimento (2018). Olericultura: Análise da Conjuntura Agropecuária. https://www.agricultura.pr.gov.br/sites/default/arquivos_restritos/files/documento/2019-09/olericultura_2019_v1.pdf.

Travsglini, C., Marchesi, M. G. \& Barbieri, M. (2021). Perspectivas 2021: Melão. O que esperar para o mercado da fruta neste ano? https://www.hfbrasil.org.br/br/perspectivas-2021-melao.aspx

Wilkinson, J. \& Castelli, P. G. (2000). A transnacionalização da indústria de sementes no Brasil: biotecnologias, patentes e biodiversidade. Actionaid.

Silva, R. S., Torres, F. E., Zanuncio, A. S., Simões, M. S., Mendonça, G. G. \& Teodoro, P. E. (2020). Caracterização de cultivares de feijoeiro comum com base no teste de distinguibilidade, homogeneidade e estabilidade (DHE). Research, Society and Development, 9(7), 1-14. 